\title{
GIJSELBRECHT VAN MEERLO, EEN GENTSE BEELDSNIJDER IN HET LAATSTE KWART VAN DE 15de EEUW
}

\author{
door Daniël Lievois 1
}

\section{Confiscatie}

Tijdens het conflict tussen de Gentenaren en Maximiliaan van Oostenrijk (1487-1492) werden in opdracht van de Stad Gent goederen aangeslagen van tal van personen die werden beschouwd als vijanden van de Stad Gent, zowel Gentse poorters als niet-poorters, waarvan men beweerde dat zij partij hadden gekozen tegen de Drie Leden van de Stad. De tweede rekening betreffende die confiscaties bestrijkt de periode van 11 november 1488 tot 7 juli $1489^{2}$. Op die laatste datum overleed Lievin Brixus, één van de beide ontvangers van de confiscaties; hij werd op 11 juli vervangen door Lodewijk de Rave. De rekening werd op 26 maart 1490 ingediend door zijn collega Jan Uuter Meere. De confiscatiemaatregel betrof ook de nalatenschap van de Gentse beeldsnijder Gijselbrecht van Meerlo. De gegevens over zijn erfenis werden opgenomen onder het kapittel van de confiscaties ten nadele van personen die in Holland verbleven. Interessant is dat er ook een los blad bewaard bleef met notities die meer licht werpen op de omstandigheden van die confiscatie, een eerder uitzonderlijke document dat de aanleiding vormde tot deze bijdrage (Bijlage 5).

Er bleef geen eigenhandig geschreven document bewaard dat toelaat vast te stellen hoe de kunstenaar zijn eigen naam spelde. In de diverse documenten komen als varianten voor Van Merlo, Meerloo, Meerelo, Merloe en Merler; er werd geopteerd voor de vorm Van Meerlo. Eénmaal werd zijn voornaam aangeduid als $G h y s^{3}$, waaruit misschien kan worden afgeleid dat hij de voorkeur gaf aan deze eerder Hollands klinkende versie, doch in contracten werd steeds de vorm Gijselbrecht gebruikt.

1 Met hartelijke dank voor de verstrekte adviezen aan: mevrouw dr. E. Dhanens, de heer prof, dr. em. A. De Schrijver en mevrouw M.C. Laleman

2 Stadsarchief Gent (verder SAG), reeks $20 \mathrm{nr}$. 5, Confiscatierekening door Jan Uuter Meere en Lievin Brixus van de absenten 1488-1489.

3 SAG, reeks $400 \mathrm{nr}$. 28, Stadsrekeningen van Gent, 1483-1484 $\mathrm{f}^{\circ} 357$. Onder meer geciteerd bij: DE POTTER, F., Gent, van den oudsten tijd tot heden, dl.2, Gent, 1884 , p. 343. 


\section{DANIEL LIEVOIS}

De persoon en het oeuvre van Gijselbrecht van Meerlo werd in enkele studies, prosopografische en andere ${ }^{4}$, vermeld, doch telkens ontbraken er elementen, die in handgeschreven notities over Gentse kunstenaars ${ }^{5}$ terug te vinden zijn. Een grondiger studie bleef achterwege, mogelijk omdat geen enkel werk aan deze beeldsnijder kan worden toegeschreven. Dit is overigens niet helemaal zeker, omdat, zoals verder zal blijken, Alphonse van Werveke in 1908 het vermoeden uitdrukte dat een retabel in het Victoria and Albert Museum (SouthKensington, London) elementen van zijn hand zou kunnen bevatten.

Het is niet bekend waar en bij wie Gijselbrecht van Meerlo zijn beroep had geleerd. Wellicht was hij afkomstig uit Holland, mogelijk uit Delft of omgeving, waar zijn enige broer en erfgenaam woonde. Hij werd als meester in de Gentse schildersnering aanvaard bij akte van 27 augustus $1471^{6}$ en beloofde toen aan deken Jan Clincke, eveneens een beeldsnijder, een toetredingsrecht te betalen van 1920 denier groot $^{7}$ en hem de traditionele zilveren schaal met vergulde rand te overhandigen; naar traditie was deze schaal in de bodem voorzien van het wapen van de nering. Van Meerlo betaalde 240 denier groot contant en kreeg uitstel om de rest te vereffenen tot Sint-Jansmis 24 juni 1478. Zijn borgen waren niemand minder dan Huughe van der Goes en Jan vanden Berghe, zoon van Laureins. Hij overhandigde zijn zilveren schaal op SintJansmis 1474 aan het bestuur van de nering in de persoon van deken Hugo van der Goes. Bij diezelfde gelegenheid stelde ook de bekende Gentse vrouwelijke schilder Agnes vanden Bossche haar zilveren schaal aan Van der Goes ter hand $^{8}$. In 1481-1482 behoorde Van Meerlo tot de raad van vier beëdigde kun-

4 DE BUSSCHER, E., Recherches sur les peintres gantois des XIVe et XVe siècles, dl.1, Gand, 1859, p. 103; VAN DER HAEGHEN, V., Mémoire sur des documents faux relatifs aux anciens peintres, sculpteurs et graveurs flamands, in: Mémoires couronnés et autres mémoires publiés par l'Académie Royale de Belgique, deel 58, Bruxelles, 1899;- CORNELIS, E., De kunstenaar in het laat-middeleeuwse Gent. I. Organisatie en kunstproduktie van de Sint-Lucasgilde in de 15de eeuw, in: Handelingen der Maatschappij voor Geschiedenis en Oudheidkunde te Gent, Nieuwe reeks, deel 41, Gent, 1987, p.118; CORNELIS, E., De kunstenaar in het laat-middeleeuwse Gent. II. De sociaal-economische positie van de meesters van de SintLucasgilde in de 15de eeuw, in: Handelingen der Maatschappij voor Geschiedenis en Oudheidkunde te Gent, Nieuwe reeks, deel 42, Gent, 1988, p. 128.

$5 \quad$ SAG, Nota's Vander Haeghen 67; Nota's Kluyskens.

$6 \quad$ SAG, reeks $301 \mathrm{nr}$. 51, Schepenregisters van de Keure, 1471-1472 $\mathrm{f}^{\circ} 4$; vermeld in: DE BUSSCHER, p. 103; VAN DER HAEGHEN, p. 57; CORNELIS, 1988, p. 128 nr. 147.

7 De bedragen in pond parisis of pond groot werden alle omgerekend in (denier) groot, waarbij een pond parisis gelijk is aan 20 groot en een pond groot aan 240 groot.

8 LIEVOIS, D., Agnes vanden Bossche, in: Agnes vanden Bossche. Een zelfbewuste vrouw en een merkwaardige kunstenares uit het 15de-eeuwse Gent, Gent, 1996, p. 26. 
stenaars die schilder Jan de Stovere, hun ambachtsdeken, bijstonden; zijn collega's waren de schilders Jan vanden Hecke en Arend van den Houte en de glasmaker Passchier Gheerolfs ${ }^{9}$. De aanstelling betekende dat hij werd erkend als deskundig in zijn vak en als vertrouwenswaardig in zijn juridische en commerciële adviezen.

\section{Woonplaatsen}

Over zijn woonplaats(en) in Gent is één en ander bekend, doch enkel een doorgedreven huizenonderzoek zou toelaten deze huizen met meer precisie aan te wijzen. Op 30 september 1479 verkocht hij voor 4200 denier groot aan Jacop van Aelst de helft en een zesde in de andere helft van een huis in de Veldstraat ${ }^{10}$. Het huis was gesitueerd tussen panden die toebehoorden aan Sanders van Vaernewyc en aan Gillis Anne en was belast met een totaal bedrag van 40 denier groot aan erfelijke renten en bovendien met een lijfrente van 240 denier groot per jaar ten gunste van de echtgenote van Rogier de Mol en van zijn zoon Lipkin. De totale waarde van het goed bedroeg dus 9760 denier groot, een bedrag dat voor die tijd op een bescheiden huis van betere kwaliteit wijst ${ }^{11}$. Hij woonde er ook daadwerkelijk, want in de akte van verkoop werd bedongen dat hij binnen het jaar zou verhuizen. Een eerste betaling van 960 denier groot gebeurde contant; de rest zou met 360 denier groot worden afbetaald telkens op 26 november en op 26 mei. Toen bleek dat de koper in 1483 nog 360 denier groot achterstallige schuld had voor de aankoop van het huis dat hij nu betrok, bracht Van Meerlo de zaak voor de schepenen van de Keure. Jacop van Aelst beloofde dit bedrag te vereffenen uiterlijk op Kerstavond $1483^{12}$.

$9 \quad$ SAG, reeks $301 \mathrm{nr}$. 56, Schepenregisters van de Keure, 1481-1482, $\mathrm{f}^{\circ} 79 \mathrm{v}^{\circ}$, akte van 17 december 1481; geciteerd bij: VAN DER HAEGHEN, p. 47.

10 SAG, reeks $301 \mathrm{nr}$. 55, Schepenregisters van de Keure, 1479-1480, $\mathrm{f}^{\circ} 10 \mathrm{v}^{\circ}$. Een mogelijk scenario dat leidde tot een dergelijke eigenaardige verdeling van het eigendomsrecht van het pand kan zijn dat Van Meerlo zijn aandeel had geërfd na het overlijden van zijn (eerste ?) echtgenote die bij haar dood vijf kinderen uit een eerder huwelijk achterliet. Wie die overleden echtgenote kan geweest zijn, kon nog niet worden uitgemaakt.

11 Op grond van de huizencategorieën in BOONE, M., DUMON, M. \& REUSENS, B., Immobiliënmarkt, fiscaliteit en sociale ongelijkheid te Gent. 14831503, in: Standen en Landen, dl. LXXVIII, Kortrijk-Heule, 1981, p. 65. De auteurs rangschikten de huizen tijdens die periode in de volgende huizencategorieën: goedkope huizen minder dan 5000 groot, bescheiden tussen 5000 en 10000 groot, vrij dure van 10000 tot 15000 groot, dure van 15000 tot 20000 groot en zeer dure huizen meer dan 20000 groot.

12 SAG, reeks $301 \mathrm{nr} .57$, Schepenregisters van de Keure, 1482-1483, $\mathrm{f}^{\circ} 195 \mathrm{v}^{\circ}$; als borg kon Jacop van Aelst rekenen op Lievin Dhooghe, zoon van Jan, een huidenvetter op de Muide. 


\section{DANIEL LIEVOIS}

Een aantal feiten wijzen erop dat Gijselbrecht van Meerlo verhuisde van de Veldstraat naar de Sint-Michielsparochie. Een eerste aanwijzing is dat hij op 21 februari 1485 aan Lievin de Muenc, alias van Lede, een achtste deel verkocht van een huis en erf in de Vleeshouwerssteeg (de huidige Gruuthusestraat). Het was gelegen achter het Hof van Gruuthuse, op de westelijke hoek van de Korenlei en de Gruuthusestraat en grensde aan beide zijden aan dit prestigieuze pand. Op het huis rustte een landcijns van 54 denier groot, wat erop wijst dat het een niet onbelangrijke woning betrof. Dit blijkt overigens ook uit het feit dat de verkoop van het achtste deel gebeurde voor 1500 denier groot ${ }^{13}$, wat toelaat de totale waarde van het huis te begroten op 12000 denier groot, een behoorlijk bedrag voor die tijd ${ }^{14}$. Van Meerlo had zijn aandeel in het pand geërfd van Janne Spelis, zyn wyfs moeye, die tevens de echtgenote was van de koper. De formulering in de akte van verkoop laat vermoeden dat de (toenmalige) echtgenote van Van Meerlo toen reeds overleden was, doch welke haar familienaam was, kon nog niet worden achterhaald. Bovendien waren er blijkbaar geen kinderen want anders zouden zij zeker in de verkoopakte vermeld zijn.

Aan deze informatie dient een ander gegeven te worden gekoppeld dat betrekking heeft op Liefkin van den Bogaerde, zoon van Gillis, zijn enige bekende leerling. Het echtpaar Lieven de Muenc en Janne Spelijs hadden immers op 9 mei 1483 een testamentaire beschikking laten registreren voor de schepenen van de Keure ${ }^{15}$. Zij hadden met beeldsnijder Gijselbrecht van Meerler (sic) een akkoord gesloten: hij zou aan Liefkin van den Bogaerde leerne de conste van beeldensnyden, terwijl het echtpaar de pupil zou bewaerne ende besorghene van ate, drancke, cleederen, coussen, scoen, lijnen ende wullen. Deze afspraak gold voor een termijn van zes jaar en was reeds ingegaan op SintMaria-Magdalenadag 22 juli 1482. Mogelijk voelde Janne Spelijs toen reeds dat haar gezondheid te wensen overliet en drong het echtpaar er daarom op aan dat deze regeling ook zou worden gehonoreerd door hun erfgenamen, wat ze bij de testamentaire beschikking lieten acteren. Uit wat voorafgaat blijkt dat Janne Spelijs alleszins voor 21 februari 1485 overleed, wat aantoont dat zij niet ten onrechte deze voorzorg had getroffen. Bovendien laat een en ander toe te veronderstellen dat Van Meerlo in de onmiddellijke omgeving woonde of dat hij zelfs inwoonde bij het echtpaar. Op het einde van zijn leven woonde hij in de Savaanstraat (hierover verder meer), doch het was vooralsnog niet mogelijk om daarover meer precieze gegevens te ontdekken.

13 SAG, reeks $301 \mathrm{nr} .58$, Schepenregisters van de Keure, 1484-1485, $\mathrm{f}^{\circ} 103 \mathrm{v}^{\circ}$.

14 Zie noot 11.

15 SAG, reeks $301 \mathrm{nr} .57$, Schepenregisters van de Keure, 1482-1483, $\mathrm{f}^{\circ} 195 \mathrm{v}^{\circ}$. Er kon niet worden uitgemaakt welke relatie er bestond tussen het echtpaar De MuencSpelijs en Liefkin van den Bogaerde. 


\section{De Sint-Walburgakerk in Oudenaarde}

Gijselbrecht van Meerlo verwierf vrij snel bekendheid in Gent en daarbuiten. Getuige hiervan is zijn vroegst bekende werk, een retabel voor de SintWalburgakerk in Oudenaarde. Het aanbestedingscontract van 19 april $1476^{16}$ bevat heel wat details (Bijlage 1). De bestelling gebeurde door ambachtsdeken Jooris vanden Eede en zijn vinders Jan vanden Raspaille en Bodin vanden Hecke, in opdracht van het Oudenaardse brouwersambacht en van de daarmee verbonden gilde van Sint-Walburga. Van het 9 voet brede en 25 voet hoge retabel bestond er een ontwerptekening op perkament, doch hierop ontbrak een beeld van de heilige Walburga dat nochtans eveneens door Van Meerlo zou worden vervaardigd. Het werk diende te worden gesneden in goed gedroogd hout dat op de juiste tijd van het jaar geveld was, opdat het nooit zou gaan trekken. Na afwerking zouden vakbekwame meesters het werk keuren en daarna werd van Van Meerlo verwacht dat hij het op zijn kosten zelf kwam opstellen in het koor van de Sint-Walburgakerk vóor 30 september 1476. De vergoeding voor de kunstenaar bedroeg 3360 denier groot, waarvan 960 denier groot contant, 960 denier groot op het einde van de maand augustus en de resterende1440 denier groot bij de oplevering. De brouwers stonden van hun kant in voor de betaling van het nodige ijzerwerk, de supplementaire houten elementen en alle taksen en tolrechten. Indien de levering niet op de gestelde tijd gebeurde, liep Van Meerlo een boete op van 960 denier groot. Meester-medicus Hoste Overryt stelde zich borg voor de kunstenaar. Uit de vermelde termijnen kan worden afgeleid dat men voorzag dat de realisatie vijf tot zes maanden tijd in beslag nam.

\section{De Sint-Janskerk in Gent}

In 1478-1479 werkte Van Meerlo aan de aanpassing van het retabel van de kapel van Onze-Lieve-Vrouw-op-de-Rade in de Sint-Janskerk. Het kerkmeubel werd weggenomen en mogelijk naar het atelier van Van Meerlo overgebracht. De machtige en rijke gilde van Onze-Lieve-Vrouw-op-de-Rade bezorgde een voorlopig dekkleed in lijnwaad daer den autaer bloet was, als de tafele van Onser Vrauwen wechghedaen was ${ }^{17}$. Ghyselbrech den beeldescnidere ontving vervolgens 720 groot van tghint dat in Onser Vrauwen tafele ghebrach te scnidene en schilder Gheerolf van den Mortele kreeg de betaling van Onser Vrauwen tafele te stofferene van scilderien ende poteraturen ${ }^{18}$.

16 SAG, reeks $301 \mathrm{nr}$. 53, Schepenregisters van de Keure 1475-1476 $\mathrm{f}^{\circ} 88 \mathrm{v}^{\circ}$.

17 Rijksarchief Gent (verder RG), Fonds Bisdom en Sint-Baafs, K 5224, Rekening van de Gilde van Onze-Lieve-Vrouw-op-de-Rade 1477-1478 f $5 v^{\circ}$. 


\section{DANIEL LIEVOIS}

Dit laatste verwijst wellicht naar zijluiken met de voorstelling van menselijke figuren. Daarbij kwamen nog kleinere uitgaven voor 2 yseren haken daer de tafele van Onser Vrauwen mede vastghemaeckt es, 2 yseren an deselve tafele, 2 slotelen van derselver tafelen en tenslotte een lijst daer de dooren vander tafelen up sluten ende rusten ende om een spiers bert ghestelt voor de apostelen; zowel het lijstwerk als het eikenhouten bebording voor de apostelen werden geschilderd ${ }^{19}$.

Aansluitend bij de vernieuwing van het retabel, werd ook de rest van de kapel opnieuw ingericht. Pieter Clincke vervaardigde een syege staende bi den sacrament, wellicht een nieuw gestoelte voor de meesters van de gilde. De meester ontving hiervoor 575 denier groot, inclusief het ijzerwerk. Aan zijn gezellen werd een extraatje van 8 denier groot toegekend als drinkgeld. Bovendien ontving den beeldesnidere van eender beelde van Marien staende up tselve werc van der syegen de som van 64 denier groot. De naam van de beeldsnijder werd niet vermeld, maar de context laat toe te veronderstellen dat ook dit Lievevrouwenbeeld(je) van de hand van Gijselbrecht van Meerlo was. Het werd gepolychromeerd door Mattys den scildere ${ }^{20}$.

\section{Leeuwenkronen in Gent}

In 1483-1484 werd Van Meerlo door het Gentse Stadsbestuur aangesproken voor het vervaardigen van de patroenen voor de kronen van de vier leeuwen die op de pilaren op de Vismarkt (nu de Groentenmarkt) werden geplaatst en waaraan één exemplaar op het Sint-Veerleplein nu nog herinnert ${ }^{21}$. De koperen kronen zelf waren het werk van kopergieter Jan van Laerbeke ${ }^{22}$, die in de desbetreffende tekst als candelermakere werd aangeduid.

\section{De parochiekerk in Nieuwerkerken}

Eveneens in 1484 volgde een retabel voor de kerk in Nieuwerkerken (Aalst) (Bijlage 3). Over dit werk zijn geen iconografische details bekend. De totale

18 RG, Fonds Bisdom en Sint-Baafs, K 5224, Rekening van de Gilde van Onze-Lieve-Vrouw-op-de-Rade 1478-1479 $\mathrm{f}^{\circ} 4 \mathrm{v}^{\circ}$. Voor Gheerolf van den Moortele, zie: CORNELIS, E., 1988, p.129 nr.153

19 RG, Fonds Bisdom en Sint-Baafs, K 5224, Rekening van de Gilde van Onze-Lieve-Vrouw-op-de-Rade 1479-1480 f $5 v^{\circ}$.

20 RG, Fonds Bisdom en Sint-Baafs, K 5224, Rekening van de Gilde van Onze-Lieve-Vrouw-op-de-Rade 1480-1481 $\mathrm{f}^{\circ} 4 \mathrm{v}^{\circ}$.

21 SAG, reeks $400 \mathrm{nr}$. 28, Stadsrekeningen van Gent, 1483-1484 f०357.

22 Zie ook: HOLLEBOSCH-VAN RECK, Y., Koper en brons, in: Gent. Duizend jaar kunst en cultuur, dl.3, Gent, 1975, p. 303, 324 en 328. 


\section{GIJSELBRECHT VAN MEERLO, EEN GENTSE BEELDSNIJDER}

prijs ervan bedroeg 1464 denier groot en werd door de kerk en de armentafel elk voor de helft vereffend. De schuldbekentenis op naam van pastoor Joos de Steercke en kerkmeester Jan de Smet werd op 26 maart 1484 geregistreerd voor de Gentse schepenen van de Keure ${ }^{23}$. Van Meerlo beschikte toen over voldoende financiële draagkracht om aan de opdrachtgevers een ruime spreiding van betaling over zes jaar te kunnen toestaan.

\section{De Sint-Niklaaskerk in Gent}

In 1486 bezorgde Jacob van Waerscoet, de deken van de nering van de corduwaniers, een nieuwe opdracht aan Van Meerlo (Bijlage 4). In functie van de nering bestelde hij een nieuw tavreel ter ere van de patroonheilige Krispijn in de ambachtskapel in de Sint-Niklaaskerk te Gent. Het aanbestedingscontract werd op 10 maart 1486 geregistreerd voor de schepenen van de Keure ${ }^{24}$. De breedte van het retabel werd bepaald door het beschikbare oostelijke muurpand in de kapel waartegen reeds eerder een beeld van Krispijn stond opgesteld. De verdere afmetingen werden nauwkeurig bepaald: den voet onder de tafle eenen voet hooghe, de tafele boom 4 voeten hooghe, de reprysen onder elken sant eenen voet hooghe, de drie beelden elc 4 voeten ende 1 alf lanc. Als werkmodel werd er verwezen naar het retabel in de Gomaruskapel in dezelfde Sint-Niklaaskerk, waarover er echter niets verder bekend is, al kan men de mogelijkheid niet uitsluiten dat het door Van Meerlo zelf was vervaardigd 25 . Voor de drie vermelde beelden werden er iconografische aanwijzingen verstrekt. Ze stelden Lazarus, Krispijn en Krispiniaan voor. Onder de voet van elk beeld diende er een koning te worden uitgebeeld. Krispijn en Krispiniaan

23 SAG, reeks $301 \mathrm{nr}$. 57, Schepenregisters van de Keure 1483-1484 $\mathrm{f}^{\circ} 140$.

24 SAG, reeks $301 \mathrm{nr}$. 58, Schepenregisters van de Keure 1485-1486 $\mathrm{f}^{\circ} 110$.

25 In de Sint-Niklaaskerk bestond er een broederschap van Job en Godemaar (Gomarus) waarvan de statuten in 1513 door de schepenen en de raad van de Stad Gent werden erkend. In 1528 beschreven de deken en de raad van bestuur hun club als 'een schoon gulde gheconfirmeert, daer ooc groote menichte van persoonen inne zijn'. Op 11 mei van dat jaar keurde het Gentse stadsbestuur een nieuw reglement voor de broederschap goed, doch het is niet met zekerheid bekend in welke kapel ze haar religieuze verplichtingen nakwam. Op grond van de associatie van Gomarus met Job, kan men het vermoeden uitspreken dat het bedoelde retabel in de latere Jobkapel was opgesteld. Het betreft de eerste kapel van de zuidelijke kooromgang die traditioneel wordt aangeduid als kapel IX (DHANENS, E., Sint-Niklaaskerk in Gent, Gent, 1960, p.22). Ze behoort tot de tweede gotische uitbreidingsfase van de Sint-Niklaaskerk in het tweede kwart van de 15 de eeuw. Of er vóór de 16 de eeuw reeds een specifieke Jobkapel bestond, is niet bekend. Indien wél, dan zal dit waarschijnlijk wel op de huidige plaats in kapel IX geweest zijn. Op grond hiervan kan men veronderstellen dat het Gomarusretabel ook daar stond opgesteld. Deze bedenkingen werden vooropgesteld in een niet gepubliceerde bouw- en kunsthistorische nota over de Kapel van Sint-Job in de Sint-Niklaaskerk te Gent door Dirk Laporte en Daniel Lievois. 


\section{DANIEL LIEVOIS}

kregen een kroon op het hoofd en een scepter in de hand. Om het geheel te bekronen voorzag men een hemel zoals die bij een retabel in de Gentse SintMichielskerk boven de beelden van Barbara, Maria en Joris. Rondom zou Van Meerlo een dubbele fries aanbrengen waartussen de gordijnen konden glijden.

Voor het gehele werk werd er tussen de contractanten een vergoeding van 3840 denier groot afgesproken. De oplevering van het vlakke werk en de hemel zonder het snijwerk was voorzien tegen Sint-Laureinsdag 10 augustus 1486 en de finale oplevering op Sint-Laureinsdag 1487. Indien de beeldsnijder zich niet aan deze termijn hield, liep hij een boete op ten bedrage van 240 denier groot. Als naar gewoonte werd er 720 denier groot contant betaald; bij elk van beide opleveringen zou de kunstenaar hetzelfde bedrag ontvangen en op Sint-Laureinsdag 1488 de resterende 960 denier groot. Indien deze betalingen niet stipt gebeurden, mocht de beeldsnijder - eigenlijk wordt hij in deze context als weercman vermeld - een supplement van 240 denier groot aanrekenen aan de nering. Zoals verder zal blijken, mocht Gijselbrecht van Meerlo de laatste betaling niet meer beleven en kwam dit bedrag van 960 denier groot aan zijn erfgenamen ten goede. Dit gegeven laat toe zijn overlijden te situeren tussen 10 augustus 1487 en 10 augustus 1488 .

\section{Confiscatie}

Zoals in de inleiding werd verduidelijkt, kwamen de ontvangers van de confiscaties in actie na het overlijden van Gijselbrecht van Meerlo. Niet enkel de beeldsnijder zelf was overleden, doch ook zijn (tweede?) echtgenote. Na hun dood verkregen haar erfgenamen de helft van de erfenis; de andere helft kwam toe aan Alaerd, de enige broer van Gijselbrecht, die in of om Delft woonde, en werd als gevolg hiervan aan confiscatie onderworpen. Hieruit kan ook worden afgeleid dat het echtpaar geen kinderen had nagelaten.

Van Meerlo had recent een huis in de Savaanstraat gekocht van de weduwe Sauwers en had naar verluidt zowat 4800 denier groot van de aankoopsom betaald. De verkoopster ontkende dit echter en daarom werd er een nader onderzoek bevolen. Het huis, in de rekening vermeld als een klein huis, werd dan verhuurd aan Jan vander Donct voor 240 denier groot per jaar. In de behandelde rekening werd de huur aangerekend voor de periode tussen SintJansmis (24 juni) 1488 en Bamis (1 oktober) 1489. Vermits er verder geen spraak meer is van de confiscatie van dit huis, mag men ervan uitgaan dat men geloof hechtte aan de bewering van de weduwe Sauwers en dat de verkoop bijgevolg werd geannuleerd.

De ontvangers van de confiscatie mochten niet enkel de inkomsten ten gunste van Alaerd van Meerlo ontvangen; zij moesten ook de schulden aanzuiveren. Zo was de beeldsnijder lid geweest van twee gilden. Het verschil in prestige 
tussen beide blijkt duidelijk uit het feit dat Gillis vanden Bossche, de klerk en ontvanger van de oude Sebastiaansgilde 60 denier groot eiste als doodschuld, terwijl Joos Danins, de deken van de Barbaragilde in de Sint-Jacobskerk, zich met 14 denier groot tevreden stelde. Opmerkenswaardig is dat Gijselbrecht van Meerlo in feite ook lid was van de oude schuttersgilde van Sint-Joris en dat hij er zich bij zijn inschrijving toe had verbonden dat zijn erfgenamen bij zijn overlijden 48 denier groot aan de gilde zouden betalen ${ }^{26}$; blijkbaar zag ontvanger Jan Uuter Meere dit over het hoofd en eiste niemand van de schuttersgilde de betaling van de schuld op.

\section{Lievin Brixus, een fraudeur?}

Beeldsnijder Jan Boone werd aangesproken als informant betreffende de erfenis. Hij volbracht deze opdracht in zijn functie van gezworene van de schildersnering 27 . Uit zijn mededelingen kan men enkel concluderen dat ontvanger Brixus wellicht meer geld had ontvangen uit de erfenis van Gijselbrecht van Meerlo dan hij aan zijn collega Jan uuter Meere had meegedeeld. Bovendien was hij bij het naspeuren van de erfenis zeker niet nauwgezet te werk gegaan. Naar alle waarschijnlijkheid verdween deze fraudezaak in de doofpot na het overlijden van Lievin Brixus en vooral na de politieke ommekeer in Gent na de Vrede van Cadzand in 1492.

In zijn rapport vermeldde Jan Boone onder meer een hoeveelheid tarwe, rogge en brandhout, doch hij kon daarover geen verdere details opgeven. Jan de Olyslagher was echter beter op de hoogte. Als erfgenaam van de dochter van de weduwe van Gijselbrecht van Meerlo had hij de helft van het koren en het brandhout ontvangen. Op de vraag om hoeveel koren en hout het ging en hoeveel geld hij ervoor had gekregen, antwoordde hij dat hij en zijn zuster een halster koren uit de erfenis hadden verkregen. Ontvanger Lievin Brixus was echter de tegenwaarde van de helft van het koren en van het brandhout komen ophalen. De deposant meende dat het brandhout 36 tot 40 denier groot per stapel waard was. Ontvanger Jan uuter Meere bleef zich evenwel afvragen of Jan de Olyslagher niet meer had betaald voor het brandhout dan wat hij had verklaard, wat erop wijst dat hij zijn overleden collega ervan verdacht een deel van het geld van de confiscatie te hebben achtergehouden.

26 Museum Bijloke, Register met de doodschulden van de oude schuttersgilde van Sint-Joris, G 12608 , deel na $1497, f^{\circ} 122 v^{\circ}$ : Ghyselbrecht van Meerloo, van Delft -4 schelling groot.

27 CORNELIS, 1988, p. 112 nr. 33. 


\section{DANIEL LIEVOIS}

\section{Nog meer kunstproducten}

Interessant zijn de inlichtingen betreffende kunstwerken die tot de nalatenschap van de beeldsnijder behoorden en die na het overlijden van de kunstenaar te gelde waren gemaakt. Beeldsnijder Jan Boone had ook hiernaar geïnformeerd en noteerde een en ander in zijn verslag. Telkens dient men zich dan ook af te vragen waar het geld was gebleven.

In de eerste plaats bleek Jan Bennins in de naam van zijn broer Martin een resterend bedrag van 480 denier groot te hebben betaald voor beeldsnijwerk geleverd voor de kapel van Sint-Martinus in de kerk van Ekkergem.

De deken van de corduwaniers van zijn kant was nog 960 denier groot verschuldigd voor eender tafele ende beeldewercke in de Sint-Niklaaskerk, waarvan het bestedingscontract hoger werd besproken. Jan de Olyslagher had dit bedrag geind als erfgenaam van de dochter van de weduwe van Gijselbrecht van Meerlo. Hij beweerde evenwel dat hij het geld meteen had doorgegeven aan Lieven de Cuervere, de deken van de bakkers, die de terugbetaling eiste van 960 denier groot die hij vooraf betaald had bij de bestelling van beeldsnijwerk dat Gijselbrecht wegens zijn overlijden niet tijdig of niet volledig had kunnen uitvoeren. De Olyslagher had toen wat graag de totale waarde van het beeldsnijwerk van het retabel van de bakkers gekend om de hand te kunnen op leggen. Dit kan erop wijzen dat de levering gebeurde na het overlijden van de kunstenaar. De schatters hadden hem dit echter niet willen meedelen tenzij hij hen het dubbele van hun vergoeding betaalde. Wél had De Olyslagher vernomen dat het ging om een totaal bedrag van omtrent 7680 denier groot. Dit was het dubbele van het bedrag dat in het hoger geciteerde aanbestedingscontract van het retabel van de corduwaniers was besproken. De Olyslagher betoogde verder dat de geldstukken van een dubbele leeuw toen 7 denier groot per stuk golden. Hij deed dit om te voorkomen dat bij een eventuele terugbetaling te zijnen gunste dit soort munten werden aangewend, want die waren ingevolge de intussen opgetreden muntontwaarding slechts 4 denier groot per stuk waard. Van wie De Olyslagher dit bedrag wenste te recupereren, wordt niet vermeld, maar ook hier was Lievin Brixus een mogelijke verdachte.

Jan Boone vermeldde verder diverse beelden die Joris de Cupere, een schilder die in de Onderstraat woonde, had verworven voor 480 denier groot. Toen de schilder hierover aan de tand werd gevoeld, beweerde hij dat Lievin Brixus zowat zes weken na het overlijden van Gijselbrecht van Meerlo bij hem thuis diversche parcheelen van ghesneden wercx, metselrie enzomeer was komen ophalen. De Cupere had hem die evenwel afgekocht voor een bedrag van 480 denier groot. Hij had toen 240 denier groot contant betaald met muntstukken van een dubbele leeuw die volgens deze zegsman toen 4 denier groot per stuk golden. Voor het resterende bedrag had De Cupere aan Brixus een 
ghezworen heyke in pand gegeven; met deze uitdrukking werd bedoeld dat Brixus gezworen had de kapmantel terug te geven wanneer De Cupere de onbrekende som had betaald. Na betaling van de resterende 240 denier groot had de vrouw van Lievin Brixus na diens overlijden de heyke inderdaad gerestitueerd, aldus De Cupere. Eens te meer kon hieruit worden geconcludeerd dat de ontvangst van dit bedrag aan zijn collega niet was meegedeeld.

De zwartzusters in Onderbergen hadden, luidens de verklaring van Jan Boone, een verguld beeld van Sint-Barbara uit de nalatenschap verworven voor een bedrag van 480 denier groot. Hierover ontstond er evenwel discussie. Jan de Olyslagher meende dat een Lievin Gommaer het beeld aan de zusters had verkocht en dan ook het geld had ontvangen. Uit een andere bron vernamen de ontvangers dat de verkoper Hendric Martins heette en dat de prijs inderdaad 480 denier groot bedroeg. Op 29 januari 1492 bevestigden zuster Vinkin Annaerts en de overste van het klooster dat zij het beeld uit het sterfhuis van Van Meerlo hadden verworven, doch zij wisten niet wie het hen had verkocht en evenmin voor wie het geld uiteindelijk bestemd was. Zuster Annaerts kon dat desgewenst wel achterhalen. De weduwe van Maerten de Hont in de Iepenstraat voegde eraan toe dat het beeld na schatting geen 120 denier groot waard bleek.

In het lijstje van Jan Boone waren er ook nog sekere witte steenen en lood die Boudin Bo(e)ne voor 60 denier groot had gekocht. Deze laatste bevestigde dit op 30 januari 1492; als verkoper noemde hij Franchois dInghelsche. De ontvangers van de confiscaties noteerden ten slotte dat hun overleden collega Lievin Brixus aan Jan van Male patroenen van scilderyen, mogelijk ontwerpen, zou hebben overgelaten ter waarde van 720 of 960 denier groot. De verdenkingen ten laste van Lievin Brixus waren al met al erg bezwarend. Zoals reeds gezegd, ontsnapte hij aan vervolging wegens zijn overlijden op 7 juli 1489, waarvan de omstandigheden in Gent trouwens druk werden besproken. Hij werd immers het slachtoffer van een moordaanslag.

\section{Moord in het Hof ten Walle}

In juli 1489 werd aan Filips de Schone een verzoekschrift voorgelegd vanwege Jan de Crooc, poorter van Gent, die de leeuwen in het Prinsenhof bewaakte en verzorgde 28 . Hij voerde deze taak uit in opdracht van Guillaume Pingion, heer van Ouberge, en was bijvoorbeeld op 11 oktober 1488 fier naar het schepenhuis getogen om een jonge leeuw aan de schepenen te presenteren $^{29}$. De Crooc was niet alleen verantwoordelijk voor de manslag op Lievin

28 Archives départementales du Nord, Lille (Frankrijk), Série B nr. 1705, Registres de l'Audience, 1488-1489, $\mathrm{f}^{\circ} 3-4 \mathrm{v}^{\circ}$.

29 SAG, reeks $400 \mathrm{nr}$. 30, Stadsrekeningen van Gent, $1488-1489 \mathrm{f}^{\circ} 92 \mathrm{v}^{\circ}$. 


\section{DANIEL LIEVOIS}

Brixus, maar bovendien had hij de wandaad gepleegd binnen de limieten van het Gentse Hof ten Walle, het latere Prinsenhof, en dus onder de jurisdictie van de vorst. Brixus én De Crooc waren beide gehuisvest op het vorstelijk domein. De Crooc vertelde dat hij als connestable de verantwoordelijkheid droeg van de wacht op de stadsvestingen van Gent en dat hij in die functie Lievin Brixus had aangemaand dat hij op Sint-Pietersavond 28 juni op post diende te zijn voor zijn waakbeurt. Brixus had dit niet enkel geweigerd, maar bovendien had hij De Crooc brutale verwijten naar het hoofd geslingerd. Op Sint-Pietersdag 29 juni zelf om zes uur 's morgens ontmoette De Crooc Brixus op het Hof ten Walle. Deze laatste verliet zijn huis in volle wapenrusting, volgens De Crooc een duidelijk bewijs van voorbedachten rade. Brixus trok meteen zijn zwaard en haalde uit naar De Crooc die verwondingen opliep in zijn gelaat en aan zijn linkerhand waardoor hij voor altijd verminkt zou blijven. De Crooc verweerde zich met zijn hellebaard, doch slaagde er niet in Brixus de raken omdat deze alle slagen afweerde met zijn ijzeren handschoen. Hij bleef De Crooc onophoudelijk bestoken met zijn zwaard met de duidelijke bedoeling hem om het leven te brengen. De gekwetste leeuwenbewaker werd gedwongen zijn hellebaard te laten vallen en slaagde er niet in zijn belager af te schudden. Daarop werd De Crooc verhit van bloede en trok een kort zwaard waarmee hij Brixus verwondde aan zijn linkerbeen, wat een eind maakte aan het duel. Brixus overleed echter acht of negen dagen later aan de gevolgen van die kwetsuur, zo beweerde men althans. De Crooc had zijn heil gezocht in de vlucht uit vrees voor het gerecht. Hij besefte evenwel dat hij niet kon blijven ontsnappen en vreesde dat hij zijn vrouw, zijn woning en zijn vijf kleine kinderen zou moeten in de steek laten. Daarom nam hij zijn toevlucht tot Filips de Schone met een verzoek om gratie, waarbij hij zich beriep op zijn goede naam en faam. De vorst pleegde overleg met zijn raadgevers, zowel zijn verwanten als de aanwezige leden van de Grote Raad, en besloot het gratieverzoek van De Crooc in te willigen en hem volkomen vrij te stellen van elke vervolging, imponerende hierup een eeuwich zwyghen. Dit laatste verwees naar het recht van de vorst om middels een impositio silentii een gerechtszaak in de doofpot te steken. De gratieverlening werd meegedeeld aan de Raad van Vlaanderen die werd verzocht het originele document te voorzien van zijn zegel omdat het zegel van Filips de Schone niet beschikbaar was. In die omstandigheden valt het beter te begrijpen dat er niet echt werk werd gemaakt van een vervolging inzake de vermoedelijke fraude door Lievin Brixus ${ }^{30}$.

30 Hoe de zaak voor Jan de Crooc verder verliep, is niet geheel duidelijk. Op 6 juli 1492 was hij nog in dienst als leeuwenverzorger. Eind september van dat jaar werd echter Jan de Meyere vermeld als bewoner van het leeuwenhuis (SAG, reeks 20 nr. 17, Bijdrage van een gulden per gezin in de Sint-Michielsparochie om de oorlogsbelasting in 1492 te betalen, $f^{\circ} 32$.). Mogelijk had De Crooc zijn job verloren omwille van de handicap die hij had opgelopen tijdens het tweegevecht, doch meer waarschijnlijk is dat hij werd afgedankt omwille van zijn sympathieën met het rebelse regime. 


\section{GIJSELBRECHT VAN MEERLO, EEN GENTSE BEELDSNIJDER}

\section{Issue}

Restte nog de fiscale afhandeling van de zaak. Alaerd van Meerlo was immers geen Gents poorter en bijgevolg diende hij aan de Stad Gent een erfenisrecht te betalen, het zogenaamde recht van issue. In dit geval werd de verschuldigde som van 684 denier groot uiteraard door Jan Uuter Meere vereffend ${ }^{31}$. De rekenplichtige van het recht van issue stond één zestiende af aan de persoon die hem de informatie over deze erfenis was komen melden. Als naar gewoonte bleef de aanbrenger anoniem. In het hoofdstuk van de issue in de Genste stadsrekening over 1489-1490 staan overigens nog meer leden vermeld van de familie Van Meerlo in Gent, doch de familierelatie met Gijselbrecht is vooralsnog niet bekend. Uit wat voorafgaat blijkt trouwens dat zij niet tot de erfgenamen van de beeldsnijder schijnen te behoren ${ }^{32}$.

\section{Conclusie}

Gijselbrecht van Meerlo was één van de vele bekwame ambachtslui en kunstenaars die naar hun beste vermogen bijdroegen tot het theatrale decorum van de Stad Gent in het laatste kwart van de 15de eeuw. Hij behoorde tot een milieu dat tal van grote figuren voortbracht, waarvan slechts weinigen een ons bekend werk hebben nagelaten. We noemen slechts de schilders Hugo van der Goes en Joos van Wassenhove en op zijn eigen vakgebied de beeldsnijder Willem Hughe. Zijn eigen oeuvre ging ongetwijfeld in grote mate teloor tijdens de beeldenstorm, doch ook tijdens de daarop volgende eeuwen. De nieuwe kunstsmaak was immers niet gediend van wat als oude rommel werd afgedaan. Daarom blijft de hoop bestaan dat er in een of andere kunstverzameling nog werk van Van Meerlo bewaard bleef, doch het valt te vermoeden dat dit voor altijd anoniem zal blijven.

In het geval van Van Meerlo deden Alphonse van Werveke en Joseph Casier een poging om althans één werk van Gijselbrecht van Meerlo aan die anonimiteit te ontrukken. Dit gebeurde tijdens een zitting van de Gentse Maatschappij van Geschied- en Oudheidkunde onder de vorm van een mon-

31 SAG, reeks $400 \mathrm{nr}$. 30, Stadsrekeningen van Gent, 1488-1489 fo21 $\mathrm{v}^{\circ}$.

32 SAG, reeks $400 \mathrm{nr}$. 30, Stadsrekeningen van Gent, 1489-1490 f० 159: Item vander versteerften van Jehannen van Meerloo wettelic wyf was van Luuc van Langheroot vanden gheheelen goede dat deelden Clais van Meerloo ende Jan Meerloo -5 schelling 2 denier groot. 


\section{DANIEL LIEVOIS}

delinge mededeling door Van Werveke op 8 april 1908, die als naar gewoonte achteraf onder vorm van een verslag in het Bulletijn werd afgedrukt ${ }^{33}$.

Van Werveke meende dat de kans reëel is dat een retabel dat bewaard bleef in het Victoria and Albert Museum in London kan geïdentificeerd worden met dat van de Kapel van Onze-Lieve-Vrouw-op-de-Rade waaraan Gijselbrecht van Meerlo werkte omstreeks 1484. Van Werveke verwees naar de talrijke archiefvermeldingen over het gesneden retabel in de kapel van Onze-LieveVrouw-op-de-Rade en vermeldde dat dergelijke vermeldingen niet meer voorkomen na het Calvinistische bewind. Hij gaf toe dat in geen enkele rekening de verkoop van een dergelijk retabel voorkomt, doch vermoedde dat de stedelijke overheid het kunstwerk van de hand kon gedaan hebben. De archiefgegevens over het uitzicht van het retabel waren volgens Van Werveke in overeenstemming met het retabel in London. Er komen inderdaad luiken aan het retabel voor en het vertoont apostelbeelden vóór een eikenhouten plank. Volgens de auteur getuigt het retabel in London van Vlaams werk van de tweede helft van de 16de eeuw. In 1531-1532 maakte beeldsnijder Jan Mijnheere een nieuwe hemel aan het retabel: ook hier zag Van Werveke gelijkenis tussen het werk in London en de hogels die in hetzelfde jaar werden gesneden voor het Gentse schepenhuis. Uiteindelijk verwees hij naar de twee flankeerkolommen die volgens hem in 1566 werden toegevoegd. Het retabel van Onze-Lieve-Vrouw-op-de-Rade was weliswaar gepolychromeerd, doch dit wees Casier van de hand omdat deze decoratie volgens hem gemakkelijk te verwijderen was.

Het ligt niet in de bedoeling dieper in te gaan op deze toeschrijving omdat dit aan deskundigen moet worden overgelaten, maar het valt wél op dat de mariale thematiek inderdaad in overeenstemming schijnt te zijn met wat men in de bedoelde kapel mocht verwachten. Treffend is hoe het middenpaneel met de Dood van Maria gelijkenis vertoont met het gelijknamige en alom bekende werk van Hugo van der Goes dat in het Groeningemuseum te Brugge wordt bewaard. Indien de toeschrijving door Van Werveke kan bijgetreden worden, mag het zelfs niet worden uitgesloten dat het een respectvolle referentie betreft naar de in 1482 overleden Gentse grootmeester die ook in het persoonlijke leven van Gijselbrecht van Meerlo een rol speelde.

33 CASIER, J., Un retable flamand à Londres, in: Bulletijn van de Maatschappij voor Geschied-en Oudheidkunde te Gent, jg. 16, Gent, 1908, p. 110111;- VAN WERVEKE, A., Un retable provenant de l'Eglise Saint-Bavon, actuellement conservé au South Kensington Museum, à Londres, in: Bulletijn van de Maatschappij voor Geschied-en Oudheidkunde te Gent, jg. 16, Gent, 1908, p. 150159. Bij dezelfde gelegenheid bracht Van Werveke ook zijn toeschrijving van het krijgsvaandel in het Bijlokemuseum aan Agnes vanden Bossche naar voren. 


\section{GIJSELBRECHT VAN MEERLO, EEN GENTSE BEELDSNIJDER}

\section{BIJLAGEN}

1. CONTRACT SINT-WALBURGAKERK OUDENAARDE 1476 Stadsarchief Gent, reeks $301 \mathrm{nr}$. 53, Schepenregisters van de Keure 14751476 f. $88 v^{\circ}$ - Ghiselbrecht van Merlo, beeldesnidere, es commen etc., kende dat hij heeft ghecomansceept ende voorwaerde ghemaect jeghen Jooris vanden Eede, als dekin, Jan vander Raspaille ende Boden vanden Hecke, als vinders van den brouambochte ende gulde van sente Wouborghen tAudenaerde, in den name vander voorseide ghemeene neeringhe, te makene ende leverne 1 tafele ghesneden naer tuutwijsen van den patrone onder hem rustende, ghemaect ende beworpen in franchine onder thantteekin van dekin ende vinders. Wel verstaende al eist zo dat in dit selve patron de beelde van sente Wouborghen niet en staet, dat nochtan voorwaerde es hij daerinne leveren moet tvoorseide beelde, naer tuutwysen ende vervolghe vanden voorseiden werke ende patroone. Al dit wesende van goeden droghen houte in tijden ende wijlen van saysoene ghevelt in zulker wijs dat niet allene noch nemmermeer en vertrecke. De selve tafle hoghe wesende 25 voeten ende 9 voeten breet, ende als van den stilen die van up deerde commen, moeten zijn dicke 6 dumen ende alle dander stilen van 3 ende 4 dumen. Voort es voorwaerde ende besprec dat hij de selve leveringhe beter leveren moet 20 schelling groot dan voorwaerde es, ende hijre af hebben sal boven den inhoudene van den patroone. Dese leveringhe doende ende waranderende bij meesters werclieden hemlieden dies bekennende ende verstaende ende emmer zulke daer toe noemende als der voorseide neeringhe ghelieven sal daer toe te nemene. Welc werc ende leveringhe de voornoemde Ghiselbrecht moet houden staende zo datter nemmermeer van corruptien eenich ghebrec in wesen sal, nemaer wezende ende zijnde goede dueghdelike leveringhe van houte ende wercke zo datter niet toe tsegghene wesen sal zonder eenighe fraude. Hiervoren es de voornoemde neeringhe etc. ghehouden te ghevene veertien pond groot vlaemsch daerop zo hy kent ghereet ontfaen hebben van dekin end vinders voornoemt 4 pond groot, ende dander 10 pond groot te betalen te wetene 4 pond groot tuutgane van ougste eerstcommende ' 76 ende 6 pond groot als hy dwerc dueghdelic ghelevert heeft naer voorwaerde. Welke leveringhe ende werc hy leveren moet tAudenaerde ende tzinen coste stellen ter plecke in sente Wouborghe choor daert behoort onthier ende den lesten dach van der maent van septembre eerstcommende, ende dan tselve werc up zine stede ghestelt zijnde inde selve kerke. Ende waert dat eenighe oncosten up tselve werc quamen int stellen ter selver plaetsen hat ware van yserwerke, onghelde, tholle of andren houtwerke dat tvoorseide bewerp uutwyst, dat moet de selve neeringhe leveren tharen laste ende coste. Ende dat Ghiselbrecht ten daghe voorscreven in ghebreke ware de voornoemde leveringhen te doene, dat ware up de peyne ende verbuerde jeghen de selve neeringhen van 4 pond groot ende tharen proffite. Ende dat hijt verbuerde, de selve voorwaerde altyts sorterende huer effecte ende van werden blivende. Al twelke den voornoemde Ghiselbrecht heeft belooft te houdene ende vulcommene dueghdelic sonder frauden ende dadt versekert up 


\section{DANIEL LIEVOIS}

hem ende up al tzine. Ende dat faulte of ghebrec ware in al dat voorseit es of in eenich point sonderlinge, zo es borghe over hem meester Hoste Overryt, medecyn, dadt insghelicx versekerende up al tzine. Actum 19a aprilis '76 naer paesschen.

\section{LEERCONTRACT LIEKIN VAN DEN BOGAERDE 1483 -}

Stadsarchief Gent, reeks 301, nr. 57, Schepenregisters van de Keure, 1482$1483, \mathrm{f} .195 \mathrm{v}^{\circ}-$ Ghiselbrecht van Meerler, beeldesnidere, an deen zijde, ende Lievin de Muenc alias van Lede ende Jaenne Spelijs, zijn wettelic wijf, an dander, kenden ende lijden, te wetene de voornoemde Lievin ende zijn wijf dat zij Liefkin van den Bogaerde filius Gillis besteet hebben te wetene metten voorseiden Ghiselbrecht omme te leerne de const van beeldensnijdene den termijn van 6 jaeren lanc gheduerende, die begonsten ende inghinc tsente Marien Maghdaleenen daghe in dit jaer ' 82 lestleden, binnen welker tijt ende termijne de voornoemde Lievin ende zijn wijf beloven den voorseiden Liefkin te bewaerne ende besorghen van ate, droncke, cleederen, coussen, scoen, lijnen ende wullen. Ende bij alsoo dat de voorseide Lievin ofte zijn wijf binnen middelen tijden der weerelt overleden, zo es haerlieder meeninghe, wille ende begheerte dat huerlieder hoyr ende naercommeren tinhauden vandien vulcommen zullen up hemlieden ende up al thuerlieden. Actum 9 may anno '83.

\section{CONTRACT PAROCHIEKERK NIEUWERKERKEN (AALST) 1484 -} Stadsarchief Gent, reeks 301, nr. 57, Schepenregisters van de Keure, 14831484, f. 140 - Her Joos de Steercke, presbiter, prochipape van der Nieuwenkercke, als over de heleghengheestmeesters, ende Jan de Smet, als kercmeester van der zelver kercken, kennen sculdich zijnde Ghyselbrecht van Meerlo, de somme van 6 pond 2 schelling groot goeder scult van den coope van eender aultaer tafele die hij der zelver kercke ghelevert heeft, te betalen deen heelft de kercke ende dander heelft de heleghegheest ende dat bij paymenten 32 schelling groot ten uutganc van marte nu eerstcommende, 32 schelling groot ten uutganc van marte int jaer ' 84 daer naer achtervolghende, 32 schelling groot gheldende tooter vulder betalinghen in zulken ghelde etc. twelke zij verzekeren upder voorseide kercke ende shelych gheest goedinghen. Actum 26 marcij anno '83 [1484 n.s.]

4. CONTRACT SINT-NIKLAASKERK GENT 1486 - Stadsarchief Gent, reeks 301, nr. 58, Schepenregisters van de Keure 1485-1486 f. $110-$ Ghiselbrecht van Merloo, beldesnydere, kende ende lyde dat hy in goede voorwaerden ghenomen heeft te makene jeghen Jacop van Waerscoet, als deken van den cordewaniers, een tavreel voor sinte Cryspine te senter Niclaus, met drie beelden daer toe behoorende ende dat in der manieren naervolghende. Te wetene tavreel plat ende also breet als den muer daer sinte Cryspyn alsnu anstaet. Item den voet onder de tafle eenen voet hooghe. Item de tafele boom 4 voeten hooghe. Item de reprysen onder elken sant eenen voet hooghe. Item de drie beelden elc 4 voeten ende 1 alf lanc. Item tselve werc in 
alder manieren te makene als twarc van sente Gommare tsenter Niclaus. Item daer boven een verwelf hemelwys ghelyc tsente Michiels boven sente Baerbelen, sente Marien ende sente Joris, ende dat metten cleenen beelden daerin staende. Item noch eenen hemele daer boven met dobbelen voyen daer de gordijnen omme loepen sullen. Item al dit weerc alzo goet of betere dan beede de voorscreven weercken zyn. Item tplatte metten hemele onghesneden moet hy leveren staende onthier ende sente Laureins daghe '86 eerstcommende. Item de drie beelden te verstane sente Lazeruse, sente Cryspijn ende sente Cryspiaen, elc eenen coninck onder huerlieder voet ende de twee leste elc eene crone up thooft ende eenen septere in de handt. Item welc voorscreven weerc al vullevert wezen moet te sente Laureins daghe ' 87 daer naervolghende, up de verbuerte van 20 scellinghe grooten ter neeringhe proffyte, ende ditte omme de somme van 16 pondt grooten, die de voornoemde dekin belooft ter kennessen van scepenen vorseyt te betaelne by paymente, te weten 3 pondt grooten ghereet, die de voornoemde Ghyselbrecht kent ontfaen hebbende ende scheldter hem dekin af quite, 3 pondt grooten tsinte Laureins daghe '87, als tweerc gheel vullent es, ende 4 pondt grooten als over de vulle betalinghe tsinte Laureins daghe '88, in zulken ghelde [...] ende ware hy dekin in ghebreke te betaelne de selve paymente, dat ware up de verbuerte van 20 scellinghe tzelfs weercmans proffite. Al twelc beede de partien belooft, bekent ende versekert hebben up hemlieden ende up al thuerlieder. Actum 10a martij anno ' 85 [1486 nieuwe stijl].

5. CONFISCATIE - Stadsarchief Gent, reeks $20 \mathrm{nr}$. 5, Confiscatierekeningen van de absenten, 1488-1489, Tweede rekening over de periode van 11 november 1488 tot 7 juli 1489, ingediend door Jan Uuter Meere op 26 maart 1490.

$\mathrm{f}^{\circ} 124$ - Ontfanc nopende zekere persoonen inwoonende ende andere hemlieden houdende in Holland - Item van Janne Bennins, over Martin Bennins zijnen broedere, ter causen vanden twee ponden grooten die hij sculdich ende tachtere stont, den hoyre van Ghijselbrecht van Merlo, beeldesnijdere was inde Sevaenstrate, ende van zijnen wive, van beelde wercke bij hem in zijnen levene ghemaect ende ghelevert inde cappelle van Sente Martin tEckerghem, over de portie ende deen heelft van dien toecommende Alaerde van Merlo te Delft in Holland oft daeromtrent, gheel hoyre vanden voornomden Ghijselbrecht, zijnen broedere was, de some van - 20 schelling groot;- Item Janne vander Donct, die in hueren gheadt heeft een cleen huus staende inde Sevaenstrate, toebehoorende den zelven steerfhuusen, omme 20 schellinghe grooten tsiaers vallende telken sente Jansmesse, ooc over de heelft van vyf vierendeelen jaers, die begonsten tsente Jansmesse acht ende tachtentich ende expirerden te Bamesse '89, de somme van -12 schelling 6 groot

$\mathrm{f}^{\circ} 124 \mathrm{v}^{\circ}$ - Van [niet ingevuld], deken vanden Cordewaniers, de somme van vier ponden grooten, die de zelve neeringhe den voornomden steerfhuuse, 


\section{DANIEL LIEVOIS}

vander leveringhe van eender tafele ende beeldewercke in Sente Niclaus kercke tachter ende sculdich stont, dus hier de zelve - 4 pond groot

$\mathrm{f}^{\circ} 171 v^{\circ}$ - Gillis vanden Bossche, als clerc ende ontfanghere vanden ouden ghulden van Sent Sebastiaen, over tdootghelt van Ghijselbrecht van Meerloo, beeldesnydere was inde Sevaenstrate, van wiens versterfte int capitle van Holland $f^{\circ} 124$ recepte ghemaect es, de somme van - 5 schelling groot;- Joosse Danins, dekin vanden ghulde van Sente Baerbelen tSente Jacops, over tdootghelt vanden voornomden Ghyijselbrecht van Meerloo - 14 groot;- Lieven de Cuervere, als dekin vanden backers, voor tghebrec van leveringhen van zekeren beeldewercke twelcke de voornomden Ghijselbrecht tsijnen overlijdene ghehouden stont der voornomde neeringhe te leverne, daer af hij de penninghen ontfaen hadde, de somme van - 4 pond groot.

6. NOTITIES OP EEN LOS BLAD Dit naervolghende zijn de parcheelen die Jan Boone verstaen heeft daer vercocht sijnde commende uuten steerfhuuse van Ghijselbrecht van Meerloo: Eerst heeft Jooris de Cupere, scildere in Donderstrate, ghecocht diversse beelden loopende tooter somme van 2 pond groot;- Item den zwarten susteren Onderberghen een beelde van sente Barbele verghult - 2 pond groot;- Item van sekere witte steenen van loete die Boudin Bone ghecocht heeft omme - 5 schelling groot;-Item van sekeren coorne, te weten tarwe ende rogghe, ende berringhe etc.;- Hendric Martins vercocht de beelde den susterkins de beelde van sente Baerbelen ende ontfinck hier af - 2 pond groot;- De weduwe sHonts upde Yperstrate Maerten sHonts wyf was vervinc zo ende kende dat de beelde naer gepresen was - 10 schelling groot;- Angaende den huuse daerin hi in woonde hy hadder up betaelt wel 20 pond groot der weduwe Sauwers die thuus behoorde ende de weduwe seyde datter niet up betaelt en was ende twaer goet dat mer naer vername;- Lievin Brixus heeft ghegheven Jan van Male patroenen van scilderyen weert zynde 3 of 4 pond groot zo Jan Boene seght;- Actum 29en january '91 - Suster Vinkin Annaerts met der moeder heeft ghedeposeert dat zy cochte een beelde van sente Baerblen int steerfhuus van Ghiselbrecht van Merlo ende hebber voren betaelt 2 pond groot, maer en weet niet jeghen wien dat zijze cochte, noch ooc wie de penninghen ontfinghen maer zy zalt vernemen;- Jooris de Cupere vervinc ten selven daghe dat Lievin Brixus haelde tzinen huus diversche parcheelen van ghesneden wercx metselrie etc. ende seide dat hy cochte ende elken penninc van 2 leuwen gingen te dier tijt te 4 grooten tstic alle de parcheelen om 2 pond groot ende hij gaf Lievin ghereet 20 schelling groot ende Lievins wijf hadde van Jooris voornomt een ghezworen heyke ende loste die heyke jeghen Lievins wyf naer toverlyden van Lievin ende dit ghebuerde ontrent 3 weken naer toverlyden van Ghiselbrecht;- Jan dOlyslager vervinc ten selven daghe dat hy ende zyn sustere hadden een halster corens ende Lieven Brixus haelde tcoren ende de berringhe tzinen huus ende was de berringhe weert elcx deel 3 schelling groot oft 40 groot ende angaende den deken vanden cordewaniers dat ghelt dat hy van hem ontfinc gaf hy ter stont den deken 


\section{GIJSELBRECHT VAN MEERLO, EEN GENTSE BEELDSNIJDER}

vanden backers ende hy seght ooc dat hy gheerne gheweten hadde den prijs vanden cateylen om selve an hem te slane maer de prisers en wilden hem den pris niet segghen zy en wilden dobbel ghelt hebben ... seght dat dat zy hem seiden dat wel ghepresen was deen heelft 16 pond groot of daer ontrent ende de dobbel leuwen hadden ganc voor 7 groot ende seght ooc de susters hadden de beelde ende vercocht se Lievin Gommaer ende ontfinc ooc de penninghen zo hy meent;- Bauwin Boene vervinc den 30 in lauwe ' 91 dat hy cochte ten sterfhuuse van Ghiselbrecht steene jeghen Franchois dInghelsche steenen etc om - 5 schelling groot;- Jan de Olyslagher was hoyr van Ghiselbrechts wyfs dochter ende hadde de heelft vanden coorne berringhen etc ende van al zy hem ghevraecht hoe vele dat hy vanden coorne ende haute ontfinc;- Item de procureurs stellen ontfaen hebbende vanden cordewaniers $f^{\circ} 124$ in de 2 de rekeninghe ende in de selve rekeninghe staet dat zy betaelt hebben den deken vanden backers f 172 - 4 pond groot;- te weten of Jan de Olislager meer gaf ter berringhe dan den boven screven ontfanc. 